\author{
Agnieszka GĄSZCZAK ${ }^{1 *}$, Grażyna BARTELMUS ${ }^{1}$, Izabela GREŃ² \\ and Daniel JANECKI ${ }^{3}$
}

\title{
KINETICS OF VINYL ACETATE BIODEGRADATION BY Pseudomonas fluorescens PCM 2123
}

\author{
KINETYKA BIODEGRADACJI OCTANU WINYLU \\ PRZEZ Pseudomonas fluorescens PCM 2123
}

\begin{abstract}
The microbial degradation of vinyl acetate (VA) by Pseudomonas fluorescens PCM 2123 strain was studied in both batch and continuous modes. The purpose of the experiments was to determine the kinetic model of the cell growth and biodegradation rate of vinyl acetate (VA), which was the sole carbon and energy source for tested microorganisms. The experiments, carried out in a batch reactor for several initial concentrations of growth substrate in the liquid phase ranging from 18.6 to $373 \mathrm{~g}_{\text {substrate }} \cdot \mathrm{m}^{-3}\left(\mathrm{~g}_{\mathrm{s}} \cdot \mathrm{m}^{-3}\right)$ made it possible to choose the kinetic model and to estimate its constants. The Haldane inhibitory model with the values of constants: $\mu_{m}=0.1202 \mathrm{~h}^{-1}$, $K_{S}=17.195 \mathrm{~g}_{\mathrm{s}} \cdot \mathrm{m}^{-3}, K_{i}=166.88 \mathrm{~g}_{\mathrm{s}} \cdot \mathrm{m}^{-3}$ predicted the experimental data with the best accuracy. To set the parameters of maintenance metabolism it was necessary to carry out a series of continuous cultures at different dilution rates $\left(0.05\right.$ to $\left.0.072 \mathrm{~h}^{-1}\right)$ and concentrations of VA in the liquid supplied to the chemostat ranging from 30.9 to $123.6 \mathrm{gs}_{\mathrm{s}} \cdot \mathrm{m}^{-3}$. The obtained data-base enabled to determine the coefficient for maintenance metabolism $\left(m_{e}=0.0251 \mathrm{~g}_{\text {substrate }} \cdot \mathrm{g}_{\text {cell dry weight }}{ }^{-1} \cdot \mathrm{h}^{-1}\left(\mathrm{~g}_{\mathrm{s}} \cdot \mathrm{g}_{\mathrm{cdw}}{ }^{-1} \cdot \mathrm{h}^{-1}\right)\right)$ as well as the maximal and observed values of yield coefficients, $Y_{x s}^{M}=0.463 \mathrm{~g}_{\mathrm{cdw}} \cdot \mathrm{g}_{\mathrm{s}}^{-1}$ and $\left(Y_{x s}\right)_{o b s}=0.411 \mathrm{~g}_{\mathrm{cdw}} \cdot \mathrm{g}_{\mathrm{s}}{ }^{-1}$, respectively. The developed kinetics was verified by comparison of the computed and obtained in batch experiments profiles of changes in biomass and growth substrate concentrations.
\end{abstract}

Keywords: vinyl acetate, Pseudomonas, kinetics, batch and continuous cultures

\section{Introduction}

The fast development of civilization over the last centuries has caused the significant increase in waste production which exceeds the possibilities of self-purification of the natural environment. The development of methods of sewage and exhaust gases treatment is the way of protection against the harmful phenomena of waste accumulation. Among them the biological processes of decomposition of pollutants play a key role because they are very effective even for very small and changeable concentrations of removed compounds as well as for large streams of treated gas [1-4].

\footnotetext{
${ }^{1}$ Institute of Chemical Engineering, Polish Academy of Sciences, ul. Bałtycka 5, 44-100 Gliwice, Poland

${ }^{2}$ Department of Biochemistry, Faculty of Biology and Environment Protection, University of Silesia, ul. Jagiellońska 28, 40-032 Katowice, Poland

${ }^{3}$ Department of Process Engineering, University of Opole, ul. R. Dmowskiego 7-9, 45-365 Opole, Poland

*Corresponding author: gaszczak@iich.gliwice.pl
} 
One of the key stages in the process of biopurification of air or sewage, which decides about its efficiency, is the rate of biodegradation of compounds which are the growth substrates for microorganisms that decompose them [5].

Hence equations describing the rate of their biodegradation are undoubtedly the essential elements in the mass balance, drawn up for any reactant, regardless of bioreactor type.

The subject of the analysis of the present study is the kinetics of vinyl acetate (VA) biodegradation by bacteria from the genus Pseudomonas.

Vinyl acetate is the unsaturated aliphatic ester which easily polymerizes to polyvinyl acetate - the basic element of bonding in glues, emulsion paints, coating materials and finishes, as well as many polymers and copolymers. In $20126.5 \mathrm{Tg}\left(10^{12} \mathrm{~g}=\right.$ million tonnes) of vinyl acetate were produced around the world, $4 \%$ more than in the previous year. Analysts predict that such a pace in production increase of VA will be maintained until 2020. Such common and quantitatively big consumption of VA, which has been included by EPA on the list of 189 the most environmentally harmful pollutants, significantly affects the emission of this compound into the atmosphere. The distribution of VA between various environmental compartments, due to its volatility and hydrolysis occurring in soil and water, is unequal. According to [6] even $91.5 \%$ of VA released into the environment pollute the air. In the air, vinyl acetate takes part in photochemical reactions, and its half-life duration in this environment is about 14 hours. In aquatic environment VA undergoes the hydrolysis to acetic acid and acetaldehyde. In the temperature of $25^{\circ} \mathrm{C}$ its half-life duration in this environment compartment is about 7 days. VA in concentration below $0.6 \mathrm{~g} \cdot \mathrm{m}^{-3}$ has no effect on freshwater fishes population but in concentration above $18 \mathrm{~g} \cdot \mathrm{m}^{-3}$ it contributes to the death of half of the freshwater algae and freshwater fishes populations [7].

Vinyl acetate is the substance whose vapours irritate the mucous membrane of eyes and upper respiratory tract and it disturbs the correct functioning of the central nervous system. International Agency for Research on Cancer (IARC) has listed VA in group 2B. It means that there is a limited evidence of its carcinogenic effect on people [8]. However, it is important to mention that soon after the contact with VA, a highly toxic acetaldehyde appears in human blood and animal tissues. Acetaldehyde directly reacts with DNA, causing formation of crosswise bonds between DNA and proteins, and chromosomal aberrations in eukaryotic cells. Toxicity of acetaldehyde, as well as the other aldehydes, can be so large that the reduction or even inhibition of bacterial cells growth from the Pseudomonas genus was observed [9, 10]. Clinical tests also proved that VA is the factor inducing nose tumours in rats [11-13].

The structure of vinyl acetate indicates that it should be easily biodegraded to carbon dioxide and water and probably that is why in literature there is little information about decomposition of this compound by microorganisms. Hatanaka et al. [14] described the process of isolation of Pseudomonas strain being able to use vinyl acetate as the growth substrate. The authors described three types of esterases present in cells of the strain, but only one of them was engaged in assimilation of vinyl acetate. Unfortunately, there is no data on conditions of its activity. Nieder et al. [15] researched the ability of decomposition of vinyl acetate by microorganisms present in samples of soil, mud, sewage under aerobic and anaerobic conditions. Two strains of yeasts and thirteen strains of bacteria which showed the ability to use vinyl acetate as the only source of carbon and energy were isolated. Among them the gram-negative strain, marked as V2, was chosen for further 
research which targeted at showing the decomposition pathway of VA. It was stated that two groups of enzymes were involved in the decomposition pathway of vinyl acetate: hydrolases and oxidoreductases. These were intracellular enzymes, and that indicates that the whole process of VA degradation occurred in cytoplasm.

Lara-Mayorga et al. [16] studied VA decomposing ability of methanogenic sludge used in the treatment of polymeric resin waste-waters. It was stated that minimal oxygenation of a reactor (about $1 \mathrm{mg} \cdot \mathrm{dm}^{-1} \cdot \mathrm{d}^{-1}$ ) resulted in the total degradation of many components, including VA, which were not utilized in anaerobic conditions. From the slightly aerated methanogenic sludge the authors isolated aerobic, gram- negative strain, identified as Brevibacillus agri strain $\mathrm{C} 1$. The comparison of vinyl acetate biodegradation rate by slightly oxygenated methanogenic sediment and strain $\mathrm{C} 1$ resulted in similar evidence, and the maximum specific rate of VA utilization was $3.98 \cdot 10^{-3}$ and $4.09 \cdot 10^{-3} \mathrm{~g}_{\mathrm{VA}} \cdot \mathrm{g}_{\text {volatile suspended }}$ solids $^{-1} \cdot \mathrm{h}^{-1}$, respectively. These results seem to prove that $\mathrm{C} 1$ strain is responsible for vinyl acetate elimination in methanogenic sediment. Gren at al. [17] selected a few environmental bacterial strains being able to grow in the presence of vinyl acetate as the only source of carbon and energy. However, comparative tests showed that VA was most efficiently utilized by the laboratory strain Pseudomonas fluorescens PCM 2123. The ability of strain PCM 2123 to metabolize vinyl acetate is connected mainly with synthesis of carboxylesterase [EC 3.1.1.1] catalysing the cleavage of ester bond. In the previous paper [18] the authors described the optimal conditions for the activity of esterase and alcohol/aldehyde dehydrogenases in the cells of PCM 2123 strain during its growth in the presence of vinyl acetate and confirmed the VA degradation pathway suggested by Nieder at al. [15].

Overriding objective of our study was to develop the bed for trickle-bed bioreactor (TBB) which could be used for purification of air containing vinyl acetate. The employment of bacteria in industrial applications could be greatly facilitated by knowledge of the growth characteristics of selected microorganisms. Therefore, the aim of further works, which are the subject of considerations in this elaboration, was to determine complete kinetic model of VA biodegradation by Pseudomonas fluorescens PCM 2123 strain. All experiments were performed in conditions ensuring the optimal activity of enzymes involved in vinyl acetate biodegradation.

It must be emphasized that, in the known literature, there was no information about kinetics of aerobic vinyl acetate degradation by microorganisms.

\section{Kinetics of bacterial growth}

\section{Batch experiments}

The exponential growth phase is essential for tests of dynamics of microorganisms growth. It is a period of balanced growth, in which all components of a cell grow at the same rate and cell mass or number increase exponentially with time $t[\mathrm{~h}]$. The rate of changes in biomass concentration in that phase is proportional to its concentration, so cell growth can be treated as the autocatalytic reaction of the first order and defined as:

$$
\frac{\mathrm{d} X_{b}}{\mathrm{~d} t}=\mu_{n e t} X_{b}
$$

where $\mu_{\text {net }}\left[\mathrm{h}^{-1}\right]$ is net specific growth rate and $X_{b} \quad\left[\mathrm{~g}_{\mathrm{cdw}} \cdot \mathrm{m}^{-3}\right]$ is biomass concentration. Integrating dependence (1) with known initial conditions $X_{b}=X_{b 0}$ at $t=0$ yields: 


$$
\mu_{n e t}=\frac{\ln X_{b}-\ln X_{b 0}}{t-t_{0}}
$$

Carrying out a series of cultures with different initial growth substrate concentrations $S_{0}\left[\mathrm{~g}_{\mathrm{s}} \cdot \mathrm{m}^{-3}\right]$ and evaluating, for each batch culture a value of the specific growth rate in the phase of sustainable growth, data base $\mu_{n e t}=f\left(S_{0}\right)$ can be obtained which allows to select the form and to estimate the kinetic equation constants [19].

In the processes of biological purification of air or sewage the key parameter, which is the measure of the process efficiency, is the rate of utilization of pollutant. Hence, it is necessary to know the parameter enabling the transformation of the equation describing the rate of biomass growth to the equation describing the rate of utilization of growth substrate.

The observed biomass yield coefficient $\left(Y_{x s}\right)_{o b s}$ is such a parameter, and it is defined as the ratio of the rate of biomass growth to the rate of utilization of substrate, measured in the same time interval of growth phase.

The substrate mass loss as a result of biodegradation, assuming thermodynamic equilibrium between the phases present in biostat, can be connected with the biomass growth via the following relationship:

$$
\frac{\mathrm{d} m_{s}}{\mathrm{~d} t}=-\frac{V_{l}}{\left(Y_{x s}\right)_{o b s}} \cdot \frac{\mathrm{d} X_{b}}{\mathrm{~d} t}=\left(V_{l}+H^{*} \cdot V_{g}\right) \frac{\mathrm{d} S_{l}}{\mathrm{~d} t}
$$

where $m_{s}\left[\mathrm{~g}_{\mathrm{s}}\right]$ is the total mass of growth substrate in both liquid and gaseous phases, $V_{L}\left[\mathrm{~m}^{3}\right]$ and $V_{g}\left[\mathrm{~m}^{3}\right]$ are volumes of liquid and gaseous phases in biostat, respectively, $S_{L}\left[\mathrm{~g}_{\mathrm{s}} \cdot \mathrm{m}^{-3}\right]$ is VA concentration in liquid phase and $H^{*}$ is dimensionless Henry's constant (for vinyl acetate $H_{30^{\circ} \mathrm{C}}^{*}=0.0261$ [20]).

Integrating dependence (3) over the time interval of the test we obtain:

$$
X_{b}=X_{b 0}+\left(Y_{x s}\right)_{o b s}\left(1+H^{*} \frac{V_{g}}{V_{l}}\right)\left(S_{l 0}-S_{l}\right)
$$

where

$$
S_{l 0}=\frac{m_{s 0}}{V_{l}+H^{*} V_{g}}
$$

and $m_{s o}$ is the mass of VA initially introduced into the biostat. Equation (4) can be rearranged to the form, which allows calculating the observed yield coefficient as follows:

$$
\left(Y_{x s}\right)_{o b s}=\left(\frac{X_{b}-X_{b 0}}{S_{l 0}-S_{l}}\right) \cdot\left(\frac{V_{l}}{V_{l}+H^{*} \cdot V_{g}}\right)
$$

\section{Growth in continuous culture}

The observed biomass yield coefficient varies usually with the growth conditions because the growth substrate is utilized not only for biomass growth but also to produce energy essential for life processes of microorganisms (maintenance metabolism) [21]. So the rate of growth substrate assimilation in the culture can be describes as:

$$
-\frac{\mathrm{d} S_{l}}{\mathrm{~d} t}=\frac{1}{Y_{x s}^{M}}\left(\frac{d X_{b}}{d t}\right)_{n e t}+m_{e} X_{b}
$$

where $m_{e}\left[\mathrm{~g}_{\mathrm{s}} \cdot \mathrm{g}_{\mathrm{cdw}}{ }^{-1} \cdot \mathrm{h}^{-1}\right]$ is the maintenance coefficient and $Y_{x s}^{M}\left[\mathrm{~g}_{\mathrm{cdw}} \cdot \mathrm{g}_{\mathrm{s}}^{-1}\right]$ denotes the maximum yield coefficient (no endogenous metabolism or maintenance energy). $Y_{x s}^{M}$ has a constant value independent of growth rate [22]. 
To set the values of $m_{e}$ and $Y_{x s}^{M}$ it is necessary to carry out the series of tests in the continuous-flow stirred-tank reactor (CFSTR) working in a steady state.

A material balance of " $i$ " compound around the chemostat can be described as:

$$
\frac{\mathrm{d}\left(C_{i} V_{R}\right)}{\mathrm{d} t}=V_{0}^{*} C_{i 0}-V^{*} C_{i} \pm r_{i} V_{R}
$$

where $r_{\mathrm{i}}\left[\mathrm{g}_{\mathrm{i}} \cdot \mathrm{m}^{-3} \cdot \mathrm{h}^{-1}\right]$ is the rate of growth/utilization of " $i$ " compound and $C_{i}$ its concentration $\left[\mathrm{g}_{\mathrm{i}} \cdot \mathrm{m}^{-3}\right]$, subscript " 0 " relates to the parameters at the reactor inlet.

The ideal chemostat is continually supplied with sterile fresh nutrient medium in the quantity of $V_{0}^{*}\left[\mathrm{~m}^{3} \cdot \mathrm{h}^{-1}\right]$ and the cultivation liquid is removed at the same rate $\left(V^{*}\right)$. It means that $V^{*}=V_{0}^{*}$ and the culture volume $V_{R}\left[\mathrm{~m}^{3}\right]$ in the reactor remains constant.

In the steady-state $\left(\frac{\mathrm{d} X_{b}}{\mathrm{~d} t}=0, \frac{d S_{l}}{d t}=0\right)$ mass balance of biomass:

simplifies to

$$
V_{R} \frac{d X_{b}}{d t}=V_{0}^{*} X_{b 0}-V_{0}^{*} X_{b}+r_{x}
$$

$$
D\left(X_{b 0}-X_{b}\right)+\mu_{n e t} X_{b}=0
$$

where $\frac{V_{0}^{*}}{V_{R}}=D\left[\mathrm{~h}^{-1}\right]$ is dilution rate.

In our experiments the feed media were sterile $\left(X_{b 0}=0\right)$ so Eq. (10) takes the form:

$$
D=\mu_{\text {net }}
$$

what means that the bacterial cells are removed from a chemostat at a rate equal to their specific growth rate.

The mass balance of growth substrate at the steady-state of the system can be expressed as:

where

$$
V_{0}^{*}\left(S_{l 0}-S_{l}\right)-V_{R}\left(\frac{1}{Y_{x S}^{M}} \mu_{n e t} X_{b}+m_{e} X_{b}\right)=0
$$

$$
\frac{1}{Y_{x s}^{M}} \mu_{n e t} X_{b}+m_{e} X_{b}=r_{s}
$$

is the rate of growth substrate utilization (Eq.(7)).

Equation (12) can be rearranged to the form:

$$
\frac{S_{l 0}-S_{l}}{X_{b}}=\frac{1}{Y_{x s}^{M}}+\frac{m_{e}}{D}
$$

or

$$
\frac{1}{\left(Y_{x S}\right)_{o b s}}=\frac{1}{Y_{x s}^{M}}+\frac{m_{e}}{D}
$$

Performing a series of experiments in a chemostat operating in the steady-state for $S_{l 0}=$ const, but with different dilution rates, and setting the corresponding value $\left(Y_{x s}\right)_{o b s}$ for each experiment, the obtained data base made it possible to plot a graph $1 /\left(Y_{x s}\right)_{o b s}$ against $(1 / D)$. According to Eq. (15), the slope of the linear regression line in the plot is $m_{e}$ and the intercept represents $\frac{1}{Y_{x s}^{M}}$ value.

In turn, performing a series of experiments at the same dilution rate ( $D=$ const), but for different concentrations of growth substrate in the medium feeding the chemostat, and 
plotting for steady-state a graph $X_{b}=f\left(S_{l 0}-S_{l}\right)$, the $\left(Y_{x s}\right)_{o b s}$ value is obtained as the slope of the linear regression line. The value of $\left(Y_{x s}\right)_{o b s}$ for any rate of dilution can be also calculated from Eq. (15) if the parameters of maintenance are known.

\section{Materials and methods}

Pseudomonas fluorescens PCM 2123 strain coming from the Polish Collection of Microorganisms, (Institute of Immunology and Experimental Therapy, Wroclaw), was applied in this study. The strain was stored in the form of lyophilizate in $-20^{\circ} \mathrm{C}$ or on agar slopes in $4{ }^{\circ} \mathrm{C}$. Proliferation of the cells and preincubation with vinyl acetate in the concentration of $0.4 \mathrm{~g}_{\mathrm{s}} \cdot \mathrm{dm}^{-3}$ was performed as described previously by Gren et al. [17]. Before proceeding with the research associated with vinyl acetate biodegradation the effect of $\mathrm{pH}$ and temperature on the growth of the selected strain was examined. Pure cultures of Pseudomonas fluorescens PCM 2123 were inoculated into a triplicate sets of $0.5 \mathrm{dm}^{3}$ Erlenmeyer flasks containing LB medium. Part of them was adjusted to $\mathrm{pH}$ of 5, 6, 7 or 8 and incubated in a shaker at $30^{\circ} \mathrm{C}$, another part was adjusted to $\mathrm{pH} 7$ and incubated at 21 , 25,30 or $35^{\circ} \mathrm{C}$. It was observed significantly weaker growth of biomass at $\mathrm{pH}=5$ and at $35^{\circ} \mathrm{C}$. Optimal environmental conditions for the growth of tested strain were $\mathrm{pH}=7$ and $30^{\circ} \mathrm{C}$.

\section{Batch experiments}

Kinetic tests were conducted in Biostat B fermentor (Sartorius, USA) of the working volume of $2.7 \mathrm{dm}^{3}$ (culture volume of $2 \mathrm{dm}^{3}$ ), whose equipment enables the control of process parameters. The experiments were conducted at the optimal environmental conditions and stirrer rotations of $300 \mathrm{rpm}$. The $\mathrm{pH}$ of the medium was adjusted to 7 by adding a $10 \%$ solution of $\mathrm{KOH}$ or $\mathrm{KH}_{2} \mathrm{PO}_{4}$. The VA degradation process was conducted under aerobic conditions but due to the volatility of VA, aeration couldn't be used. To assure that the culture wasn't limited by $\mathrm{O}_{2}$ a constant DO (dissolved oxygen) concentration (about $5 \mathrm{mg} \cdot \mathrm{dm}^{-3}$ ) was achieved by dosage with a $0.75 \%$ solution of hydrogen peroxide according to the indications of sensor. Preliminary tests confirmed the activity of catalase in cells of strain $P$. fluorescens PCM 2123 [23].

The tests were conducted for initial concentrations of VA changing within the range of 18.6-373 $\mathrm{g}_{\mathrm{s}} \cdot \mathrm{m}^{-3}$. Each cultivation was started with the similar cells concentration in a solution which was about $9 \cdot 10^{-2} \mathrm{~g}_{\mathrm{cdw}} \cdot \mathrm{dm}^{-3}$ and that corresponds to absorbance about 0.2 at $\lambda=550 \mathrm{~nm}$.

During experiments, at particular time intervals, the concentrations of biomass, VA and indirect products of metabolism (acetaldehyde, acetic acid and ethanol) were determined.

\section{Continuous culture}

Each continuous culture was initially run as the batch one and no fresh medium was added. As soon as the culture was achieving the exponential growth phase and enough biomass has been formed, the sterile medium supplemented with the appropriate amount of growth substrate was supplied. The chemostat suspension was periodically sampled. When no appreciable change in cell mass and substrate concentration was observed - changes do not exceed $3 \%$ in the subsequent analyses - it was considered that the steady state was reached. The culture was kept at least for the time necessary for seven changes of liquid in 
bioreactor. Two series of experiments were conducted: for $D=0.072 \mathrm{~h}^{-1}$ changing VA concentration in a liquid feeding chemostat within the range of $15-123.6 \mathrm{~g}_{\mathrm{s}} \cdot \mathrm{m}^{-3}$, and for VA concentration in a liquid feeding chemostat equalling to $123.6 \mathrm{~g}_{\mathrm{s}} \cdot \mathrm{m}^{-3}$, changing the dilution rate within the range of $0.05-0.48 \mathrm{~h}^{-1}$.

\section{Analytical methods}

Biomass concentration was indicated by spectrophotometric method as described earlier [15]. Concentration of VA and indirect products of its biodegradation were defined with the help of Varian 3800 gas chromatograph as described previously [17]. Every test was repeated twice in identical conditions, and the values were averaged to get the true experimental value.

\section{Results and discussion}

\section{Batch experiments}

Batch experiments were conducted to investigate the effect of initial vinyl acetate concentrations on Pseudomonas fluorescens PCM 2123 growth. For each periodic culture the graph $\ln X_{b}=f(t)$ was prepared. In the exponential growth phase the dependence is a straight line whose slope determines the value of the specific growth rate $\mu_{\text {net }}$ [24]. The obtained data base was presented in Figure 1 in the form $S_{l 0} / \mu_{n e t}$ against $S_{10}$. The curve approximating the experimental points is parabola (not straight line) so clearly indicates the inhibition of biomass growth by the limiting substrate [19].

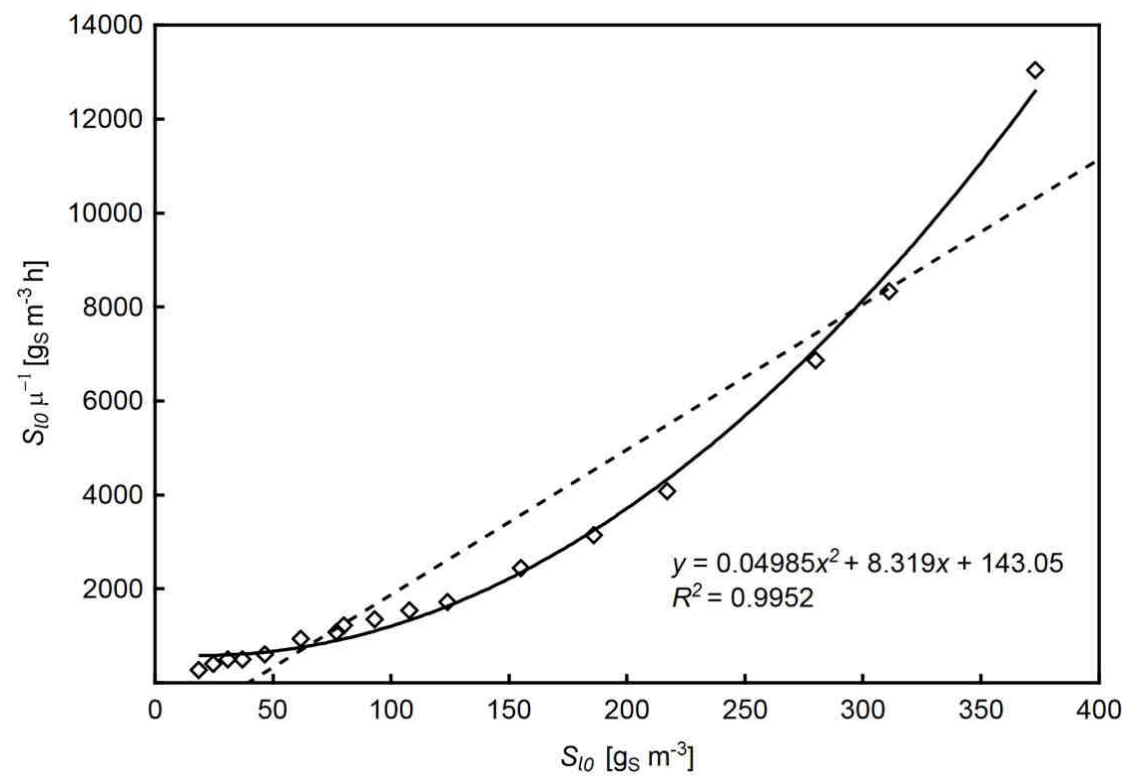

Fig. 1. The graph of dependence $S_{10} / \mu_{\text {net }}=f\left(\mathrm{~S}_{10}\right)$ for VA biodegradation by Pseudomonas fluorescens PCM 2123 
A lot of suggestions of equations describing kinetics of microorganisms growth inhibited by substrate can be found in literature. They were drawn up by Singh et al. [25], Agarry et al. [26] and in monographs of Moser [19] and Shuler and Kargi [22]. All tested equations (Aiba, Haldane, Teissier, Yano-Koga) approximated experimental values with the mean relative error $e_{Y}$ not exceeding $11 \%$, so the most frequently applied the Haldane equation was chosen to describe Pseudomonas fluorescens PCM 2123 strain growth on VA:

$$
\mu=\frac{\mu_{m} S_{l}}{K_{s}+S_{l}+\frac{S_{l}^{2}}{K_{i}}}
$$

where $\mu_{m}\left[\mathrm{~h}^{-1}\right]$ is the model parameter, $K_{S}$ and $K_{i}$ are the half saturation constant $\left[\mathrm{g}_{\mathrm{s}} \cdot \mathrm{m}^{-3}\right]$ and substrate inhibition constant $\left[\mathrm{g}_{\mathrm{s}} \mathrm{m}^{-3}\right]$, respectively.

The kinetic equation parameters were estimated based on the own database using the least-square error method with the help of NLREG programme [27], and they are: $\mu_{m}=0.1202 \mathrm{~h}^{-1} ; K_{s}=17.195 \mathrm{~g}_{\mathrm{s}} \cdot \mathrm{m}^{-3}, K_{i}=166.88 \mathrm{~g}_{\mathrm{s}} \cdot \mathrm{m}^{-3}$. Developed equation with a mean relative error:

$$
e_{Y}=\frac{1}{N} \sum_{i=1}^{N}\left|\frac{\mu_{\text {exp }, i}-\mu_{c a l c, i}}{\mu_{\text {exp }, i}}\right| \cdot 100 \%
$$

not exceeding $8.5 \%$ approximates the experimental data. In Eq. (17) subscripts exp and calc denote experimental and calculated values, respectively.

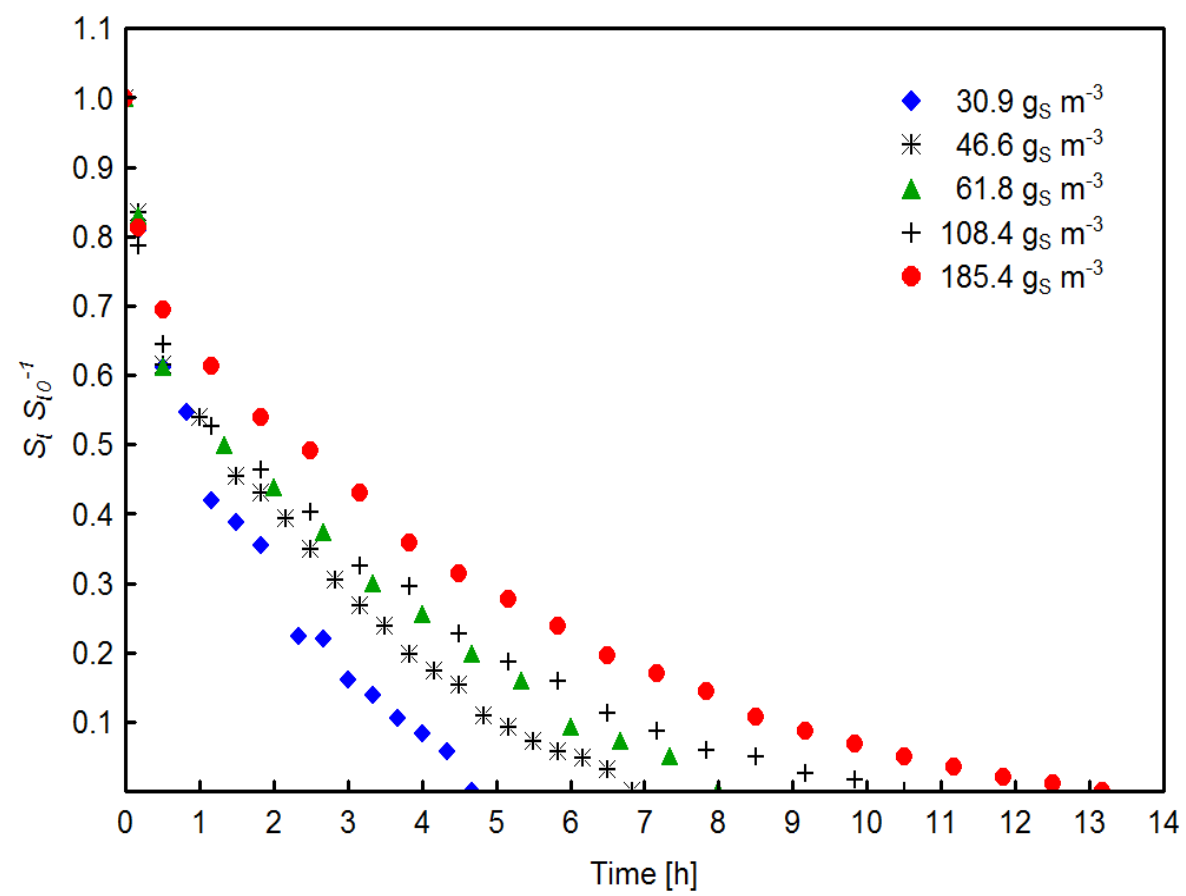

Fig. 2. Profiles of changes in VA concentration during individual cultures $P$. fluorescens PCM 2123 on VA at different initial doses of substrate 
No data referring to kinetics of vinyl acetate utilization which could be compared with results of this elaboration was found in literature.

For estimation of the observed yield biomass coefficient it was necessary to trace the changes in growth substrate concentration in each periodic culture at regular intervals. It was noted that every time after addition of the particular amount of VA to biostat the reduction of VA concentration was observed but biomass growth did not accompanied it (Fig. 2).

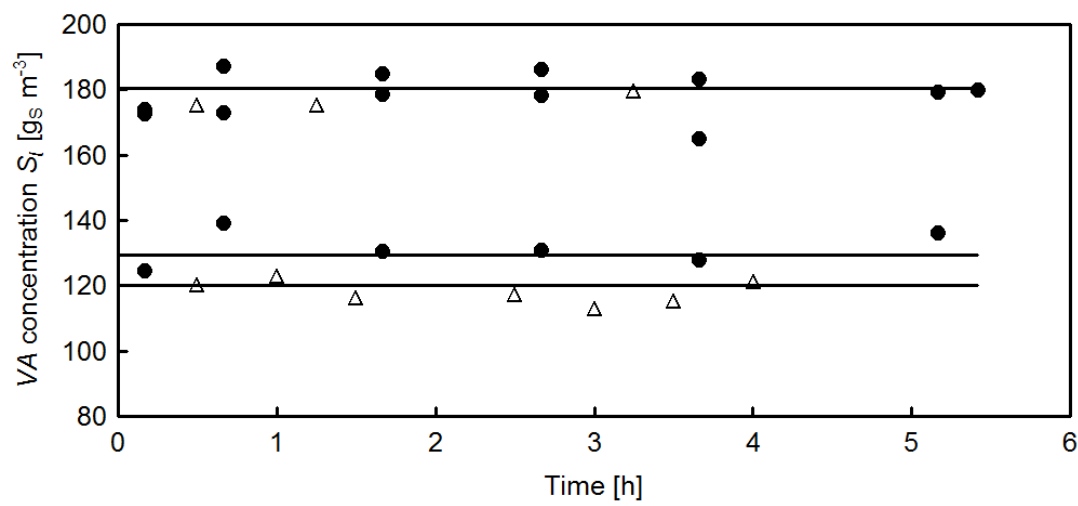

Fig. 3. Changes in VA concentration in sterile solutions of mineral medium (filled symbols) and solution with inactive bacteria (open symbols)

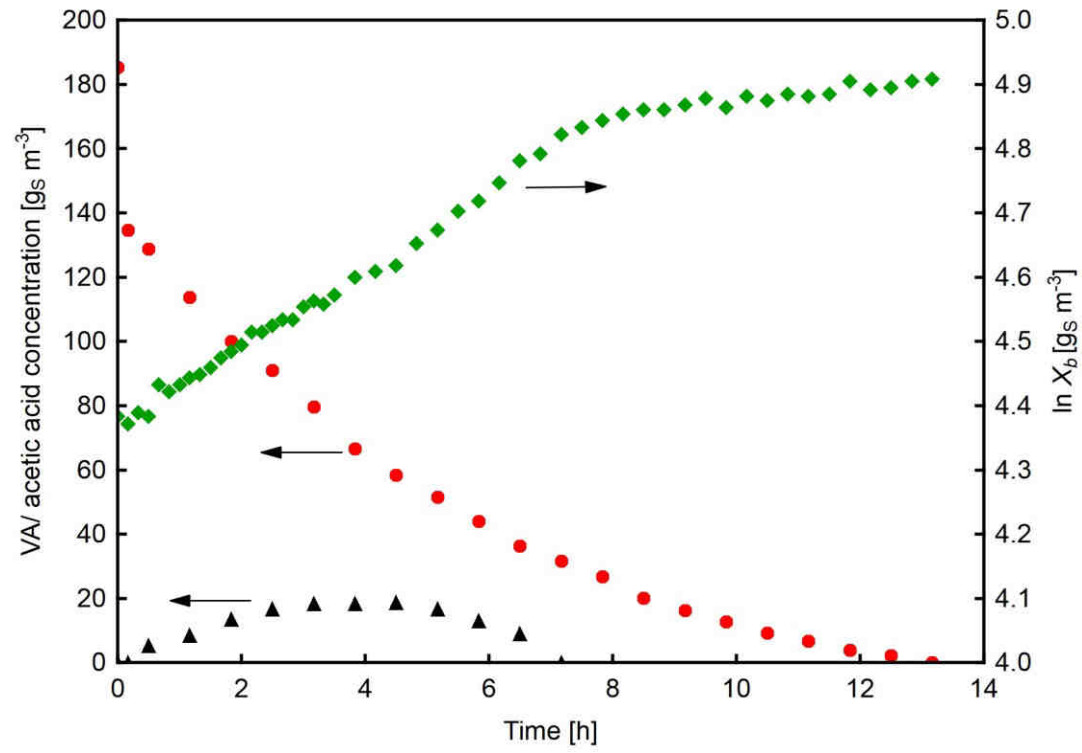

Fig. 4. Profiles of changes in time of the concentrations of biomass (diamonds), vinyl acetate (circles) and acetic acid (triangles) 
To check this is the feature of the tested system series of experiments, maintaining the same parameters as in the kinetics studies, were carried out either without bacteria cells or with microorganisms which were earlier sterilized in autoclave for $1.5 \mathrm{~h}$ at $121^{\circ} \mathrm{C}$. In both tests, after a few hours of experiment duration, there was no substrate reduction as a result of nonenzymatic hydrolysis (Fig. 3). According to literature data, the half-life degradation of VA as a result of this process varies from $60 \mathrm{~h} \mathrm{[15]} \mathrm{to} 168 \mathrm{~h}$ [7].

The results shown in Figure 3 seem to confirm the hypothesis that the observed reduction of substrate concentration in the initial cultivation stage is connected with vinyl acetate assimilation by Pseudomonas fluorescens PCM 2123 cells and its biodegradation by the intracellular enzymes [18]. However, the exact reason is unclear. It must be added that during cultivations, in the whole range of the tested VA concentrations, no presence of acetaldehyde and ethanol was indicated. For concentrations of VA higher than $185 \mathrm{~g}_{\mathrm{s}} \cdot \mathrm{m}^{-3}$ acetic acid appeared in a solution, but it was utilized in the phase of sustainable growth (Fig. 4).
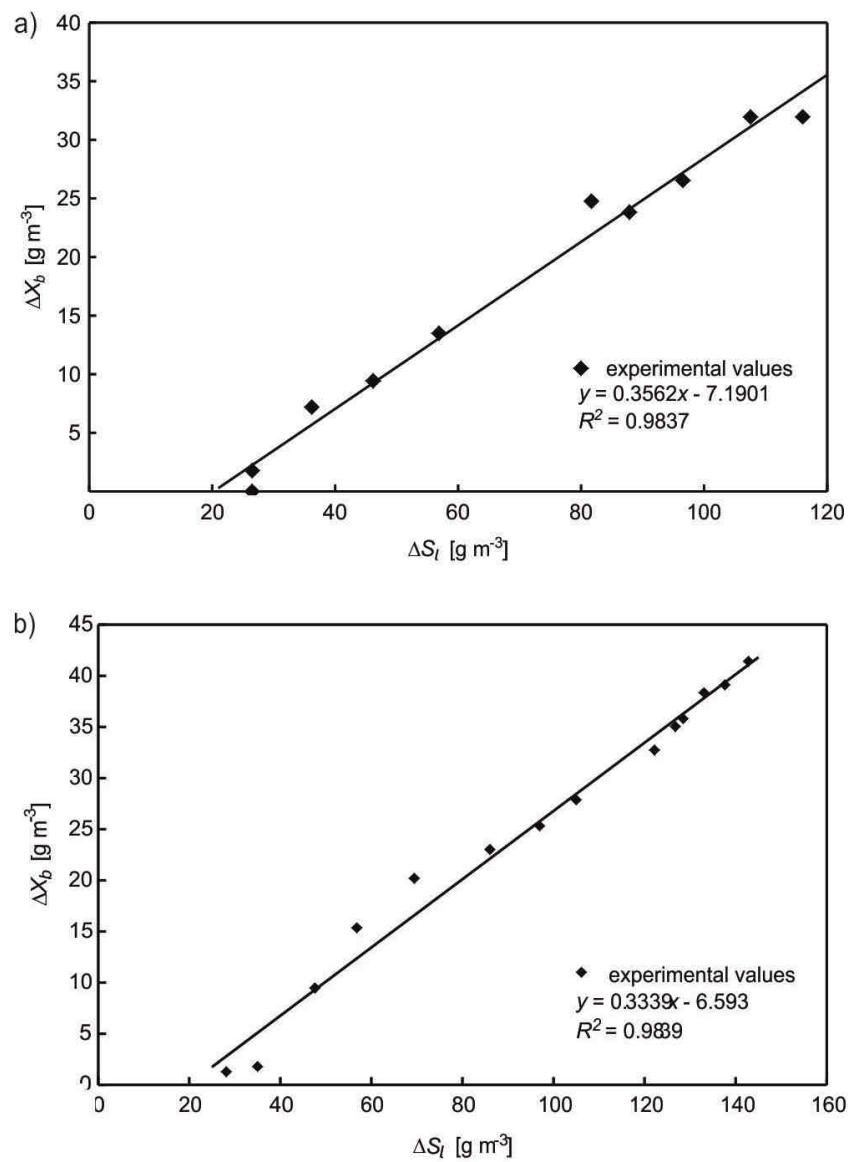

Fig. 5. Illustration of the method of estimation $\left(Y_{x s}\right)_{o b s}$ value for: a) $S_{l 0}=123.6 \mathrm{~g} \cdot \mathrm{m}^{-3}$ and b) $S_{l 0}=154.5 \mathrm{~g} \cdot \mathrm{m}^{-3}$ 
Taking into account all data mentioned above, $\left(Y_{x s}\right)_{o b s}$ was estimated by preparation for each culture in the exponential growth phase, the graphs $\Delta X_{b}=f\left(\Delta S_{l}\right)$, like Bakhshi et al. [24] and Nweke et al. [28] carried out before.

From the slope of straight line which approximated experimental points, the value $\left(Y_{x s}\right)_{o b s}$ was read off (Fig. 5). The estimated in this way value of the observed yield biomass coefficient $\left(Y_{x s}\right)_{o b s}$ changed slightly with the change of the specific growth rate, and its mean integral value determined in the range of the tested changes of the initial VA concentration was 0.37. The value of $\left(Y_{x s}\right)_{o b s}$ was verified in the tests carried out for continuous culture of Pseudomonas fluorescens PCM 2123 cells with VA as the only source of carbon and energy.

\section{Continuous cultures}

For the values of operational parameters $\left(D, S_{l 0}\right)$ used in the experiments the presence of acetaldehyde, acetic acid and ethanol was not noticed in the liquid leaving chemostat.

Based on the results of research conducted in the chemostat, values yield coefficients, maintenance coefficient and maximum specific growth rate can be designated.

The first series of experiments was performed for the constant concentration of VA in a medium fed into the chemostat $\left(S_{l 0}=123.6 \mathrm{~g}_{\mathrm{s}} \cdot \mathrm{m}^{-3}\right)$, but changing dilution rate. In Figure 6 the results of continuous culture of Pseudomonas fluorescens PCM 2123 in the presence of vinyl acetate as the dependence $1 /\left(Y_{x s}\right)_{o b s}=f(1 / D)$ for the cultures carrying out at the dilution rate changed in the range $0.05-0.0721 \mathrm{~h}^{-1}$ were noted. The experimental points were approximated with a straight line, whose slope defines the value of maintenance coefficient $\left(m_{e}=0.0251 \mathrm{gs}_{\mathrm{s}} \cdot \mathrm{g}_{\mathrm{cdw}}{ }^{-1} \cdot \mathrm{h}^{-1}\right)$, but intercept is converse of $Y_{x s}^{M}$ which equals to $0.4633 \mathrm{~g}_{\mathrm{cdw}} \cdot \mathrm{g}_{\mathrm{s}}^{-1}$. In this way the parameters of Eq. (15) has been determined.

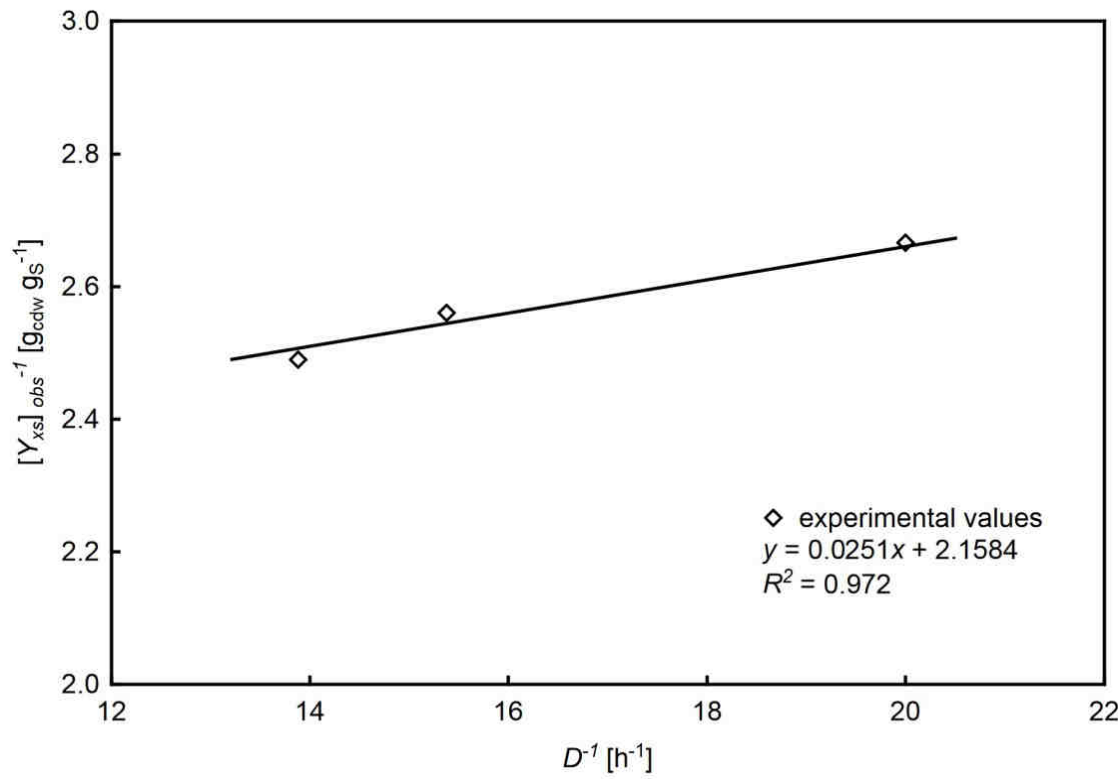

Fig. 6. Plot of function $\left(Y_{x s}\right)_{o b s}{ }^{-1}$ versus $D^{-1}$ for $S_{l 0}=123.6 \mathrm{~g} \cdot \mathrm{m}^{-3}$ 
The maximum specific growth rate $\mu_{m}$ is often estimated from continuous cultures experiments using the method of wash-out. Unfortunately, it was not possible to determine the $\mu_{m}$ value due to strong ability of tested strain to biofilm formation at higher $\left(D>0.09 \mathrm{~h}^{-1}\right)$ dilution rate. These observations corroborate the findings of Molin [29] who stated that the common methods of calculating $\mu_{m}$ from a chemostat experiments are not reliable when a biofilm is present.

Figure 7 shows the results of another series of continuous cultures conducted with the steady dilution rate $\left(D=0.072 \mathrm{~h}^{-1}\right)$ for various VA concentrations in a medium feeding chemostat. The slope of line approximating experimental data indicates the value $\left(Y_{x s}\right)_{o b s}$ equalling $0.369 \mathrm{~g}_{\mathrm{cdw}} \cdot \mathrm{g}_{\mathrm{s}}{ }^{-1}$. This value of $\left(Y_{x s}\right)_{o b s}$ is almost identical to the value of $\left(Y_{x s}\right)_{o b s}$ obtained as integral average from the batch tests. The difference between the determined experimentally and calculated from equation (15) values of $\left(Y_{x s}\right)_{o b s}$ didn't exceed $8 \%$.

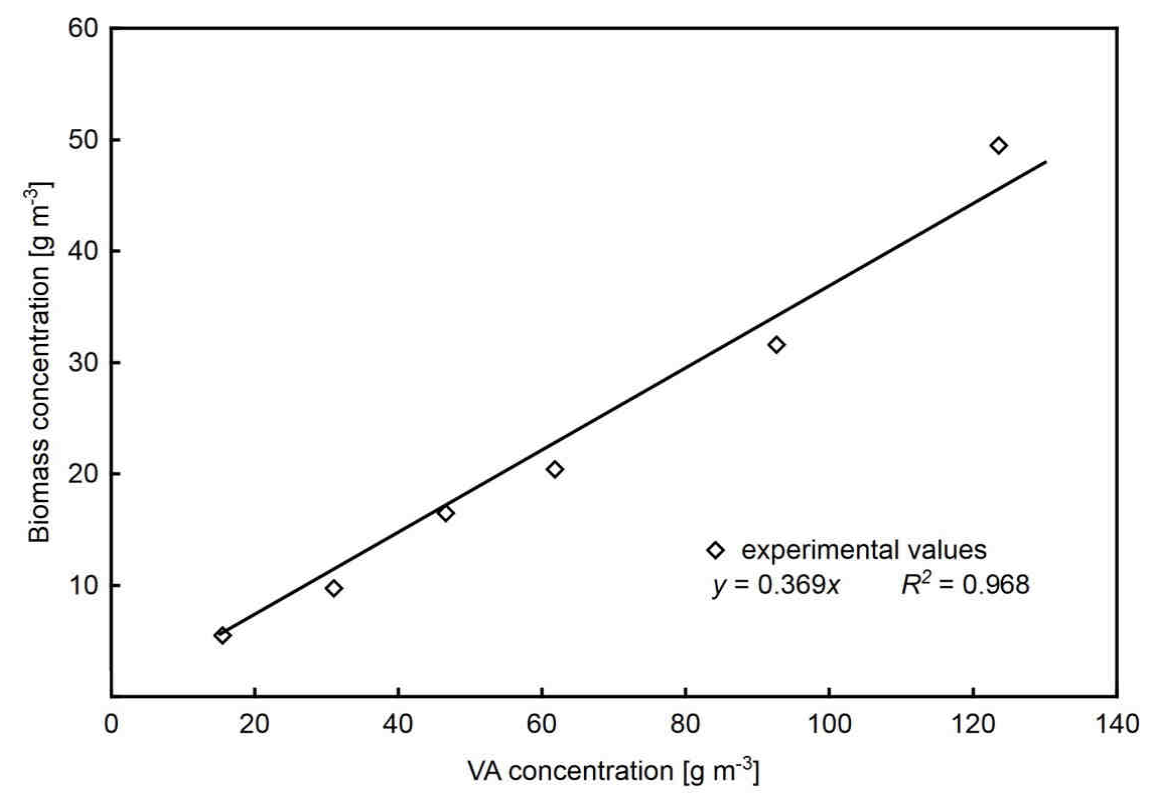

Fig. 7. Plot of function $X_{b}=f\left(S_{l 0}-S_{l}\right)$ for different concentrations of VA in nutrient solution supplied to chemostat; $D=0.072 \mathrm{~h}^{-1}$

\section{Verification of kinetic model}

The determined complete model of growth of Pseudomonas fluorescens PCM 2123 cells in the presence of vinyl acetate allows to calculate the profiles of the changes of biomass and growth substrate concentrations in the periodic cultures. For this purpose the system of differential equations must be solved:

$$
\frac{\mathrm{d} X_{b}}{\mathrm{~d} t}=\left(\frac{0.1202 S_{l} X_{b}}{17.195+S_{l}+\frac{S_{l}^{2}}{166.88}}\right)\left(1-\exp \left(-\frac{t}{t_{l}}\right)\right)
$$




$$
-\frac{\mathrm{d} S_{l}}{\mathrm{~d} t}=\frac{1}{0.4633}\left(\frac{\mathrm{d} X_{b}}{\mathrm{~d} t}\right)+0.0251 X_{b}
$$

The last term on the right hand side of Eq. (18) considers existence of adaptation phase of duration $t_{l}$. The above system of equations with the initial condition:

$$
\text { when } t=0 \text {, than } X_{b}=X_{b 0} \text { and } S_{l}=S_{l 0}
$$

was solved by Runge-Kutta $4^{\text {th }}$ order method.
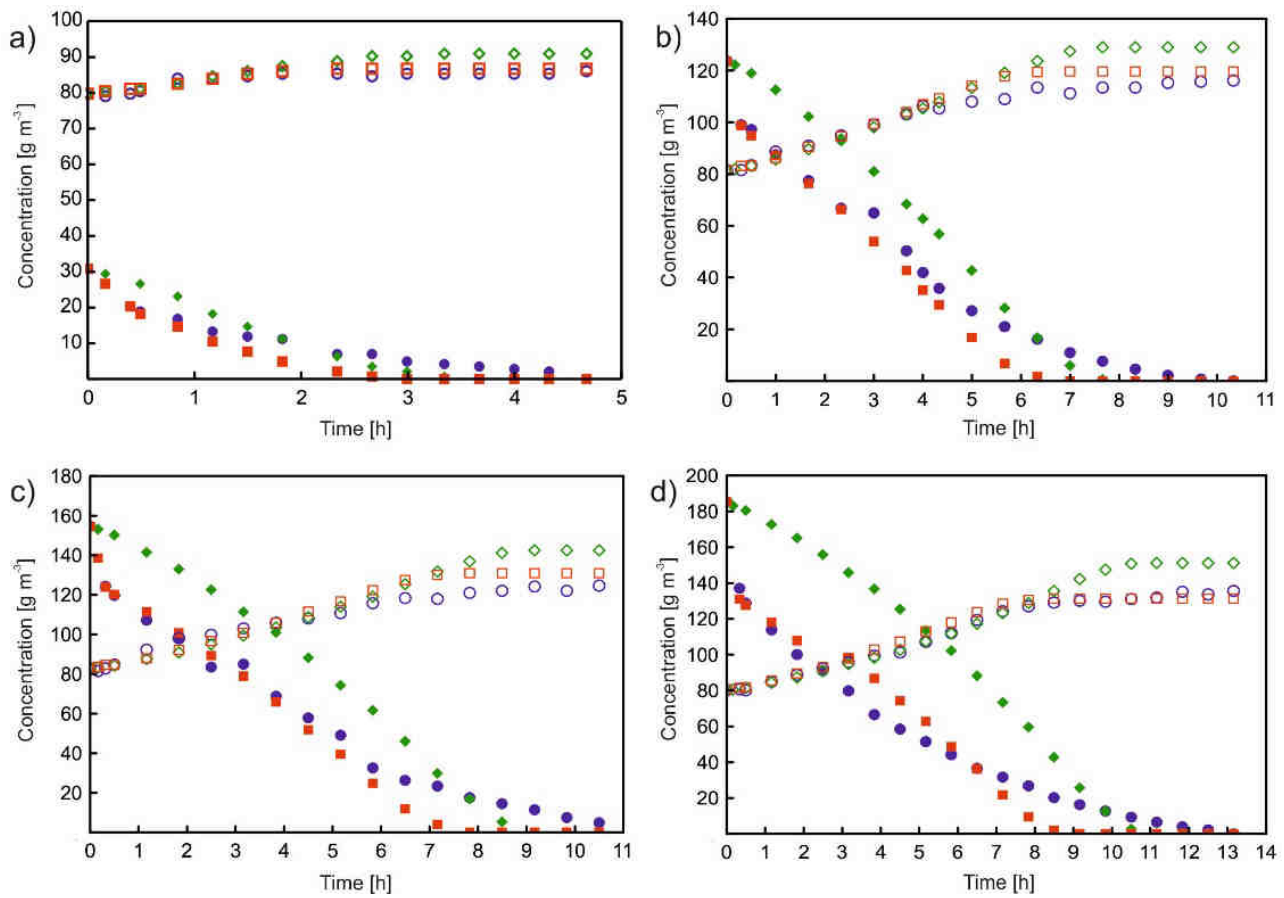

Fig. 8. Profiles of changes in concentration of biomass (open symbols) and VA (filled symbols) for different initial concentrations of growth substrate $\left(S_{l 0}=30.9 \mathrm{~g} \cdot \mathrm{m}^{-3}(\mathrm{a}), S_{l 0}=123.6 \mathrm{~g} \cdot \mathrm{m}^{-3}(\mathrm{~b})\right.$, $S_{l 0}=154.5 \mathrm{~g} \cdot \mathrm{m}^{-3}(\mathrm{c})$ and $S_{l 0}=185.4 \mathrm{~g} \cdot \mathrm{m}^{-3}(\mathrm{~d})$. circles - experimental values, diamonds - values computed using set of Eq. (18) and (19), squares - values computed using set of Eq. (21) and (22)

Unfortunately, such a formulated kinetic model does not take into account the sorption of growth substrate in lag phase, observed during experiments. In that situation, the method of calculation of the profiles of growth substrate was modified. First, on the basis of experimental data, the concentration of substrate at the end of lag phase was defined, whose value was marked as $S_{I}^{L}$. Next the system of equations was solved:

$$
\frac{\mathrm{d} X_{b}}{\mathrm{~d} t}=\left(\frac{0.1202 S_{l} X_{b}}{17.195+S_{l}+\frac{S_{l}^{2}}{166.88}}\right)
$$




$$
-\frac{\mathrm{d} S_{l}}{\mathrm{~d} t}=\frac{1}{0.4633}\left(\frac{\mathrm{d} X_{b}}{\mathrm{~d} t}\right)+0.0251 X_{b}
$$

with the initial condition:

$$
\text { when } t=t_{L} \text {, than } X_{b}=X_{b 0} \text { and } S_{l}=S_{I}^{L}
$$

such method of fitting the calculated and obtained experimentally results was also applied by Hao et al. [30] for chlorophenol utilization by Acinetobacter species.

In Figure 8 the profiles of changes in biomass and VA concentration calculated and obtained experimentally for a few periodic cultures of Pseudomonas fluorescens PCM 2123 cells were compared.

It is worth emphasizing that the results of numerical simulations performed using set of Eqs. (21) and (22) fit the experimental values with good accuracy. Only in a final phase of balanced growth the calculated values are slightly lower than the experimental ones. It may be supposed that when the growth substrate depletes the microorganisms utilize stocks of energy stored in the first phase (lag phase) of cultivation. It seems to confirm the conclusion of Nieder et al. [15] who noted that the whole substrate, even that one sorbed in the first phase of cultivation (in lag phase), was accessible for microorganisms in the latter phases of growth.

\section{Conclusions}

The presented work presents the issues associated with making use of microorganisms to remove the selected volatile organic compound which was the only source of carbon and energy. A large experimental data base made it possible to estimate the constants of kinetic equation, to determine the yield coefficient and maintenance parameters. The worked out kinetic model was verified basing on our own experimental data base. It should be emphasized that the rate of biodegradation of the growth substrate is one of the most important stages of the processes taking place in bioreactor. The formulated relationships are necessary to verify the mathematical model of the bioreactor since drawing up mass balance of the compound removed from the air or sewage, regardless of the type of a bioreactor, requires a knowledge of an expression determining the biodegradation rate of the removed pollutant.

The experiments showed high activity of tested microorganisms in the process of biodegradation VA and relatively low sensitivity to the inhibitory influence of VA at higher concentrations in solution (the high value of $K_{i}$ ). Due to such feature, the examined microorganisms may be recommended as biological material in the processes of removing VA from waste air and sewages.

To our knowledge this is the first elaboration in which the complete kinetic data for the VA degradation by strain from genus Pseudomonas was investigated.

\section{References}

[1] Sakunthala M, Sridevi V, Chadana Lakshmi MVV, Vijay Kumar K. A review: the description of three different biological filtration processes and economic evaluation. JECET. 2013;2:91-99. https://www.jecet.org/download_frontend.php?id=63\&table=Archive.

[2] Cheng Y, He H, Yang Ch, Zeng Ch, Li X, Chen H, Yu G. Challenges and solutions for biofiltration of hydrophobic volatile organic compounds. Biotechnol Adv. 2016;34;1091-1102. DOI: 10.1016j.biotechadv.2016.06.007. 
[3] Zdeb M, Lebiocka M. Microbial removal of selected volatile organic compounds from the model landfill gas. Ecol Chem Eng S. 2016;23:215-228. DOI: 10.1515/eces-2016-0014.

[4] Świerczyńska A, Bohdziewicz J, Puszczało E. Treatment of industrial wastewater in the sequential membrane bioreactor. Ecol Chem Eng S. 2016;23:285-295.DOI: 10.1515/eces-2016-0020.

[5] Ferdowsi M, Ramirez AA, Jones JP, Heitz M. Elimination of mass transfer and kinetic limited organic pollutants in biofilters: A review. Int Biodeter Biodegr. 2017;119;336-348. DOI: 10.1016/j.ibiod.2016.10.015.

[6] Federal Institute for Occupational Safety and Health Division for Chemicals and Biocides Regulation Vinyl Acetate - Summary Risk Assessment Report. Dortmund (Germany): 2008. https://echa.europa.eu/documents/10162/6434698/orats_summary_vinylacetate_en.pdf.

[7] Vinyl Acetate Safe Handling Guide. Washington: Vinyl Acetate Council; 2010. http://msdssearch.dow.com/PublishedLiteratureDOWCOM/dh_0916/0901b803809160d4.pdf?filepath=vam $\&$ fromPage $=$ GetDoc.

[8] http://toxnet.nlm.nih.gov/cgi-bin/sis/search/r?dbs+hsdb:@term+@rn+108-05-4).

[9] Jakoby WB, Narrod SA. Aldehyde oxidation IV. An aldehyde buffer for growth studies. J Bacteriol. 1959;77:410-413. https://jb.asm.org/content/jb/77/4/410.full.pdf.

[10] Simon P, Filser JG, Bolt HM. Metabolism of pharmacokinetics of vinyl acetate. Arch Toxicol. 1985;57:191-195. https://link.springer.com/content/pdf/10.1007/BF00290886.pdf.

[11] Bogdanffy MS, Sarangapani R, Plowchalk DR, Jarabek A, Andersen ME. A biologically based risk assessment for vinyl acetate-induced cancer and noncancer toxicity. Toxicol Sci. 1999;51:19-35. DOI: 10.1093/toxsci/51.1.

[12] Bogdanffy MS, Taylor ML. Kinetics of nasal carboxylesterase-mediated metabolism of vinyl acetate. Drug Metabol Dispos. 1993;21:1107-1111. http://dmd.aspetjournals.org/content/21/6/1107.short.

[13] Morris JB, Symanowicz P, Sarangapani R. Regional distribution and kinetics of vinyl acetate hydrolysis in the oral cavity of the rat and mouse. Toxicol Lett. 2002;126:31-99. DOI: 10.1016/S0378-4274(01)00442-8.

[14] Hatanaka Y, Inoue Y, Murata K, Kimura A. A isolation and characterization of carboxylesterase from vinyl acetate-assimilating bacterium isolated from soil. J Ferment Bioeng. 1989;67:14-19. DOI: 10.1016/0922-338X(89)90079-2.

[15] Nieder M, Sunarko B, Meyer O. Degradation of vinyl acetate by soil, sewage, sludge, and the newly isolated aerobic bacterium V2. Appl Environ Microbiol. 1990;56:3023-3028. https://www.ncbi.nlm.nih.gov/pmc/articles/PMC184893/.

[16] Lara-Mayorga I, Duran-Hinojosa U, Arana-Cuenca A, Monroy-Hermosillo O, Ramirez-Vives F. Vinyl acetate degradation by Brevibacillus agri isolates from a slightly aerated methanogenic reactor. Environ Technol. 2010;31:1-6. DOI: 10.1080/09593330903260904.

[17] Greń I, Gąszczak A, Guzik U, Bartelmus G, Łabużek S. A comparative study of biodegradation of vinyl acetate by environmental strains. Ann Microbiol. 2011;61:257-265. DOI: 10.1007/s13213-010-0130-4.

[18] Szczyrba E, Greń I, Bartelmus G. Enzymes involved in vinyl acetate decomposition by Pseudomonas fluorescens PCM 2123 strain. Folia Microbiol. 2014;59:99-105. DOI: 10.1007/s12223-013-0268-0.

[19] Moser A. Bioprocess Technology, Kinetics and Reactors. New York: Springer-Verlag; 1988. DOI: 10.1007/978-1-4613-8748-0.

[20] EPA On-line Tools for Site Assessment Calculation. http://www3.epa.gov/ceampubl/learn2model/ part-two/onsite/esthenry.html.

[21] Pirt SJ. The maintenance energy of bacteria in growing cultures. Proc R Soc London B. 1965;163: $224-231$.

[22] Schuler ML, Kargi F. Bioprocess Engineering. New Jersey: Prentice Hall, PTR; 2002. ISBN 9780130819086.

[23] Takeuchi M, Weiss N, Schumann P, Yokota A. Leucobacter komagatae gen. nov., sp. nov., a new aerobic Gram-positive, nonsporulating rod with 2, 4-diaminobutyric acid in the cell wall. Int J Syst Bacteriol. 1996;4:967-971. DOI:10.1099/00207713-46-4-967.

[24] Bakhshi Z, Najafpour G, Kariminezhad E, Pishgar R, Mousavi N, Taghizade T. Growth kinetic models for phenol biodegradation in a batch culture of Pseudomonas putida. Environ Technol. 2011;32:1835-1841. DOI: 10.1080/09593330.2011.562925.

[25] Singh RK, Kumar Sh, Kumar S, Kumar A. Biodegradation kinetic studies for the removal of p-cresol from wastewater using Gliomastix indicus MTCC 3869. Biochem Eng J. 2008;40:293-303. DOI: 10.1016/j.bej.2007.12.

[26] Agarry SE, Solomon BO. Kinetics of batch microbial degradation of phenols by indigenous Pseudomonas fluorescens. IJEST. 2008;5:223-232. http://www.bioline.org.br/pdf?st08026.

[27] Sherrod PH. Nonlinear Regression Analysis Program (NLREG). Nashville: TN; 2010. www.nlreg.com.

[28] Nweke CO, Okpokwasili GC. Kinetics of growth and phenol degradation by Pseudomonas species isolated from petroleum refinery wastewater. Int J Biosci. 2014;4:28-37. DOI: 10.12692/ijb/4.7.28-37. 
[29] Molin G. Measurement of the maximum specific growth rate in chemostat of Pseudomonas spp. with different abilities for biofilm formation. Eur J Appl Microbiol Biotechnol. 1983;18:303-307. DOI: 10.1007/BF00500496.

[30] Hao O, Kim M, Seagren E, Kim H. Kinetics of phenol and chlorophenol utilization by Acinetobacter species. Chemosphere. 2002;46:797-807. DOI: 10.1016/S0045-6535(01)00182-5. 